\title{
MIND AND MEDIUM IN ART'. (II.)
}

\author{
By A. B. WALKLEY.
}

Mr MarRIotr opens his enquiry by approaching art from without, and the close of it finds him, I think, left still outside. He takes the 'practical' view of aesthetics, as distinguished from the 'theoretic,' which, in its innumerable varieties, has been the view normally taken throughout the history of the science, from its Greek beginnings to the present day. Indeed, he takes the ultra-practical or 'craftsman's' view. "Craft," he says, "is a necessary condition of art, and the nature of art and of aesthetic appreciation can be studied profitably only in that condition." This is an extreme position. Mr Marriott will not take it as a reproach, but, from his own statement, as a compliment, if $I$ call it, as Greek criticism would have called it, 'banausic.'

He starts with the familiar fact that construction is modified by materials. A stone cross naturally takes a different shape from a wooden cross. The forms of classical architecture were conditioned by the use of long stones. In the transition from writing to printing script changed as the practical conditions changed. Conclusion: "practical and aesthetic reasons are at bottom the same thing"-or "aesthetic appreciation is dependent upon the sense, which may not be conscious, of practical problems effectively solved." I fail to see how this conclusion logically follows from these premises. Because practical reasons have not been ignored in the aesthetic field, does it necessarily follow that there are no others? That they are "the same thing" as aesthetic reasons? Is conformity to the nature of the material the sole criterion of beauty? "Aesthetic appreciation is dependent upon the sense, etc." Is this true; or should we prefer to say "includes the sense"?

But Mr Marriott is firm about it. "Art is primarily the characteristic use of materials." Imagination (I use the word to cover both his "representation" and "design") is merely incidental-and may not be there at all. Tools and materials are 'the thing.' "The limitation of art through craftsmanship results in the expression of what we call personality." Some people would call this putting the cart before the

1 A contribution to the Symposium presented at the Congress of Philosophy in Oxford, 24-27 September, 1920. 
horse. They would say that the expression of personality, in the process of externalisation, has to use craftsmanship. I will return to that later. But we are already a long way from the notion of art as a spiritual activity, as an operation of the mind.

And Mr Marriott's "practical theory covers "all art." "All art is the record of human gestures in the presence of the subject or idea and as conditioned by the nature of the medium in which they are made." It seems to me this definition is at once (1) too complete and (2) incomplete. It is too complete, for it covers life as well as art. When a fly settles on your nose you wrinkle your nose and lift your hand to brush it off-both hum:n gestures made in presence of the subject and conditioned by the medium, your own body. The record of these gestures would be, not art, but history. Similarly, with all the gestures, say, in Darwin's Expression of the Lmotions in Man and Amimals. Again, the definition is incomplete, because the word 'gesture' presents an incomplete image. Gestures of what? we say. Gesture is movement with meaning. It is the expression of something. It is the outward and visible sign of something inward and spiritual. And what can that inward and spiritual thing be but the very object of our search, the aesthetic fact?

Here we come to the kernel of the subject. It seems to me that you may go on considering gestures for ever and yet be as far as ever from possessing the aesthetic fact, the 'true inwardness' of art. 'The outward and visible sign will never conduct you to what is inward and spiritual. Broad washes will not explain to you the beanty of the water-colour, nor long stones, characteristically used, the beauty of the Parthenon. "Once aceustom a mim to the idea that art is primarily the characteristic use of tools and materials in view of the particular purpose, and you have given him a clue to the highest aesthetic appreciation." You will at best, I venture to think, have given him a clue to appreciation of the characteristic use of tools and materials. Hard by the Parthenon stands the little temple of Nikè; down below them in the town is the temple of Theseus. In each building the architect has used long stones characteristically; yet while that practical condition has never been lost sight of, three different beautiful forms have been produced, each of them an individual thing. How can you account for this save by reference to the artist's mind, his artistic impulse, vision, inspiration-call it what you will? Long stones used characteristically did not make these buildings what they severally were; the artist used them to embody his imaginative vision, the art in him. Take another illustration from a very different 
form of ant -..drama. It is one of the commonplaces of Shakespearean criticism that Shakespeare's plays were conditioned by the practical circumstances under which they were produced. They were produced on a 'platform' stage, and therefore show some peeuliarities which would be out of place on our modern 'picture' stage- - c.g. an exeess of narrative and lyrieal passiages. The dramatic action of Hamlet is interrupted while the Queen lyrically describes Ophelial's death. Shakespeare makes her do this for "practical reasons" (the conditions of the platform stage). But do these 'practical reasons' account for the aesthetic fact, the pure poetic beauty of the passage? Mr Marriott would have to say yes; for "practical and aesthetic reasons are at bottom the same thing." There you have a case where the artist has nsed his medium characteristically, as they used the long stones in the Parthenon; but the characteristic use of the medium would never huve given you a che to the beatuty of the passage, which was contribited by Shakespeare, the poet. Further, Shakespeare had, like other dramatists, to consult the tastes and expectations of his audience. 'This was one of his 'practical' conditions. How did he meet it? Professor Raleigh puts the answer pithily. "The audience asked for bloodshed and he gave them ILamlet. They asked for foolery, and he gave them King Lear." Shakespeare, then, effectively complied with the practical conditions of his problem, as did the architect of the Parthenon with his long stones. But effective compliance with practical conditions will no more account $f_{c} \cdot$ the beanty of the l'arthenon than it will for the beauty of Lear and Hamlet.

Are we not forced then to the conclusion that this 'practical' investigation advocated by Mr Marriott, the consideration of 'gestures,' medium, material and tools, can never answer the fundamental question, what is Art? The enquiry from withont having failed to bring us to the goal, may we not have better luck by trying the method of enquiry from within? After all, that is the normal method. The history of aesthetics through the ages runs mainly along that line. Aestheticians, from Plato onwards, have nearly all agreed in supposing that art is primarily a 'function,' as the mathematicians say, of the artist's mind rather than of his medium or of his tools. Instead, that is to say, of seeking to penetrate to the secret of art through broad washes and long stones, they began, so to speak, at the other end and considered art as a spiritual activity. One point of view, Mr Marriott's, says every landseape is the characteristic use of paint and brush in the presence of a corner of nature. For the other point of view you have Amiel's "every landscape is a state of the soul." 
What is the dominant theory to-day among aestheticians who have pursued the traditional line, of considering art as a 'function' of the artist's mind? It is the expressionist theory of Benedetto Croce. "Art and Beauty are one and the same thing, and that thing is an experience of the human spirit. We might even say that it is the simplest of all such experiences, and the earliest. Whenever a human being concentrates his total feeling into an image which is at once its essence and its utterance, the spirit of art is awakened. Beauty, in other words, lives in the creative imagination, and there alone, and art is nothing more and nothing less than the experience which we call beauty. All else is irrelevant. True an? false, real and unreal, good and bad, have no place in the aesthetic world. Here nothing counts but the perfection of the imaginative act in itself, and by its own standard. And this is in principle all that we need to know about the beautiful. It has no subdivisions within itself, and its manifestations array themselves in no kind of series. Aesthetic philosophy lies in explaining the scale of beauty among the experiences of the spirit, and in defending the simplicity of the principle against traditional but unjustified intrusions. This is the meaning of Croce's doctrine that beauty is expression. And that doctrine is sound ${ }^{1}$."

I have purposely quoted Dr Bosanquet's exposition of Croce because he is one of Croce's most formidable critics-and, as it happens, he is most formidably critical of Croce's handling of the very subject now under discussion, the relation between art and medium. For Croce this relation is purely external, a relation not within the aesthetic fact, but between the aesthetic fact, which is pure intuition-expression, and a particular moment in the historic situation of the artist. Croce holdsit is his cardinal position-that the aesthetic activity is purely internal, the expression within the mind of the artist's intuition. He may or may not, as he chooses, extrinsicate his expressions, communicate them to others in pictures, statues, and other so-called 'works of art.' But the real work of art is the internal expression, of which the picture or statue is only a practical record. Of course the artist does not work in vacuo. His aesthetic activity is exercised in a certain historic situation-at a given moment of time, in certain surroundings, with a certain mind and temperament. His intuitions will depend on the circumstances of his historic situation and, if he externalises them in 'works of art,' these circumstances will include his medium and tools and the joy (since every practical end successfully achieved involves joy) of "using" them, in Mr Marriott's phrase, "characteristically." But they remain

1 Bernard Bosanquet, “Croce's Aesthetic," Brit. Acad. Proc. Ix. 
always 'historic situation'; they are never 'art.' This abolishes the distinction between the arts according to the media or means of externalisation. "Since the individuality of the intuition involves the individuality of the expression, and a picture is distinct from another picture no less than from a poem, and pictures and poems are not of value for the sounds that strike the air and for the colours that are refracted by the light, but for what they have to say to the spirit in so far as they come home ( $s^{\prime}$ interiorizzano) to the spirit, it is vain to turn to the abstract means of expression to construct the other series of kinds or classes; that is to say any theory whatever of the division of the arts is without foundation ${ }^{1}$."

Of course the 'man in the street' will never swallow this. With him, perhaps, it would be idle to argue on a question of philosophy. But the man in the street has on this issue a potent philosophic ally, Dr Bosanquet, whose high authority as an aesthetician makes it impossible to ignore him. He is all for the old division of the arts. "After all it is necessary for philosophy to study the specialities and limits of the arts, for in considering them we are considering the qualities and aspects of the human spirit; nay more, of the spirit which is in the world. If you know or can feel how the beauty of bronze-that is, its expressive capacity-differs from the beauty of marble, you are on the way to understand the diverging beauties of the arts; and if you insist on neglecting these affinities of the spirit, your theory remains abstract, and has no illuminating power ${ }^{2}$. No illuminating power! For my part, I find a theory which (apart from its general applications) unifies all the so-called 'arts' and shows me their common basis one of the most "illuminating" in the whole history of aesthetics. Not that Croce denies-who could?the practical value of the old classification of the arts. Indeed, he expressly insists on $\mathrm{it}^{3}$. What he denies is its theoretic value: its place in a philosophy of aesthetics. "To reject," says Dr Bosanquet, "the function of the body-our own and nature's-is not to honour but to bereave the spirit." But Croce does not reject it; he simply removes it out of a particular category.

Elsewhere ${ }^{4}$, Dr Bosanquet, I submit, does injustice on this point to Croce by an imperfect quotation. "Croce says that the artist has every stroke of the brush in his mind as complete before he executes it as after. The suggestion is that using the brush adds nothing to his inward or mental work of art. I think that this is false idealism. The bodily thing

1 Breviario di Estetica, 71.

2 Bosanquet, loc. cit. 12.

3 Croce, op. cit. 72, 7:3.

4 Bosanquet, Three Lectures on Aesthetic, 73. 
adds immensely to the mere idea and fancy, in wealth of qualities and connections." Now what Croce says (Estetica, Ch. XIII, end) is: that the artist "never gives a stroke of the brush without having first seen it with the imagination; and if he has not yet seen it, he will give it, not to extrinsicate his expression (which in that moment does not exist), but as it were on trial, and to have a mere point d'appui for further meditation and internal concentration." The stroke of the brush, that is, gives him a new 'historic situation,' from which he will have a new intuition. The bodily thing, then, does not 'add' to the idea and fancy; it creates a new milieu for the idea and fancy to work in and so to produce new expressions. Croce is trying to isolate the aesthetic fact in the idea and fancy; Dr Bosanquet says no, you must include the bodily thing, the milieu, in it, too. According to Croce, "the old aesthetician Baumgarten advised poets, as a means of promoting inspiration, to ride, to drink wine moderately, and, if they were chaste, to look at pretty women." Schiller, the common anecdote goes, used to smell rotten apples for the same purpose. These are all 'historic situations.' Would Dr Bosanquet include them in the aesthetic fact, too?

Finally, there can be no question of tabulating the consequences and advantages of the Crocean view of art, as Mr Marriott does with his view, because that would carry us far beyond the limits of the present discussion-the relation of art and medium. It will be seen, however, from what has been said, that Croce sweeps a way not only the false distinctions that Mr Marriott abolishes but also those that he retains; not only the distinction between representative and non-representative art and the distinction between the various forms of the same art, but also the distinction between one art and another. Further, he not only, with Mr Marriott, brings all practitioners of the same art into the same category, but all men, in the act of expression, into the single category of the artist. 